\title{
Real-Time Dynamic Thermal Rating Method to Uprate the Ampacity of Overhead Transmission Lines: A Case Study
}

\begin{abstract}
Asanka S. Rodrigo and S. Rishanthi
Abstract: $\quad$ Traditionally, Static Thermal Rating (STR) calculates current carrying capacity based on "Worst case weather conditions", which is used by most of the utilities around the world including Sri Lanka. Assumptions made in the STR calculations may reduce the actual line capacity whenever real weather conditions are less stressful. However, the smart-grid technology based Real Time dynamic Thermal Rating (RTTR) allows to utilize the overhead line conductors by increasing the current carrying capacity of the line based on real time weather data. The identification of critical span to ensure the minimum electrical clearance is the major consideration to ensure the safety of the people and equipment when applying RTTR method. This paper presents a method to introduce real time thermal rating to overhead transmission lines in Sri Lanka. Current rating of lines is calculated using real time weather data. In here, the selected line sections have been analysed using PLSCADD software with RTTR design. This novel methodology can be used by system operators to analyse weather based current ratings for the transmission network in future.
\end{abstract}

Keywords: Real time thermal rating, Overhead line monitoring, Weather-based current rating

\section{Introduction}

Demand for electricity is increasing rapidly with technological growth and improvement in the quality of life. As a result of the increased power flow, some transmission lines that are close to their maximum ampacity limits become overloaded while introducing bottle necks into the system. When conductor is overloaded it will violate the maximum allowable conductor temperature [1]. An excessive conductor temperature may give rise to an excessive elongation of the conductor with consequent dangerous reduction of the electrical clearances to ground. All these effects caused by an excessive current may put public safety at risk. To overcome this issue, current carrying capacity of those lines have to be increased with conventional methods like using higher rating conductors or higher ampacity lower sag conductors, or by reconstructing the line using the same Right Of Way (ROW). However, these are not possible for some lines because of line interruptions will be a big issue in urban areas where most of the industrial loads are carried by these lines.

Existing transmission lines have been designed and operated using static or fixed thermal ratings that limit the amount of power that can be transferred. This current carrying capacity is restricted by maximum allowable conductor temperature, which determines the maximum sag of the line [2]. During planning and designing stages, the current carrying capacity of overhead conductors has been historically calculated using worst case weather conditions such as highest ambient temperature, highest solar intensity, lowest wind speed, etc [3]. But, in reality, weather parameters widely vary depending on time, place and season [4]. Introducing real time thermal rating method to these lines will increase the line current carrying capacity by monitoring the weather parameters in real time. Advantage can be taken from real time weather, which is not always be the worst, by adopting RTTR method.

Not only for existing lines, for the new wind farm interconnections, the transmission lines with equal capacity need to be installed. Since higher wind speed will increase both wind power generation and current carrying capacity by convection cooling, RTTR method can offer most economical solutions for use of transmission line capacity by using low rating smaller diameter conductors [5]. If there are generation clusters connected by transmission lines with lower capacity than dispatchable combined generation, then the RTTR method can be used very effectively. RTTR method is

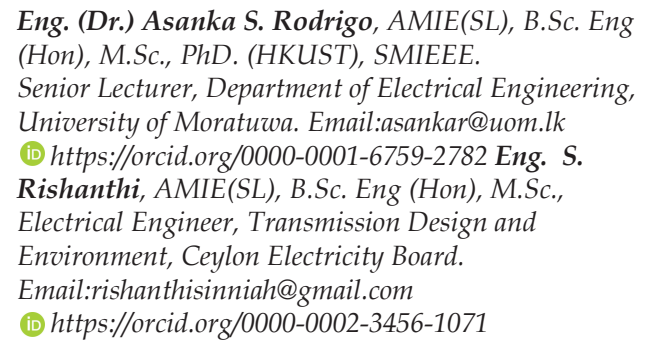


being slowly adopted by the world now. Sri Lanka itself had some network constraints for several years because of delaying projects due to varies reasons like social, environmental, political, funding etc. Absorbing RTTR method to Sri Lankan transmission network will reduce network restrictions and utilize the conductor more efficiently and safely.

\section{Literature Review}

Current Carrying Capacity (CCC) of a conductor depends on [3],[6]:

- Conductor material properties

- Conductor diameter

- Conductor surface condition

- Weather conditions

- Conductor temperature

For a given conductor, the first two properties are the same and, in a shorter period, the surface condition of a conductor will not change rapidly. Maximum permissible conductor temperature shall be given by the manufacturer or utility [1]. Following are the weather parameters which influence the CCC of a given conductor [3],[6].

- Ambient temperature

- Solar intensity

- Wind speed

- Wind angle

There are two types of thermal rating methods available when calculating the current carrying capacity of a conductor:

- Static thermal rating

- Real-time dynamic thermal rating

Heat balance equation 1 is used to calculate current carrying capacity of a given conductor. Heat losses due to convection and radiation $\left(Q_{c}, Q_{r}\right)$ is equal to solar heat gain $\left(Q_{s}\right)$ and heat gain due to conductor resistance $\left(R\left(T_{\text {avg }}\right)\right)$.

$Q_{c}+Q_{r}=Q_{s}+I^{2} \cdot R\left(T_{a v g}\right)$

Where,

$$
R\left(T_{\text {avg }}\right)=\left[\frac{R\left(T_{\text {high }}\right)-R\left(T_{\text {low }}\right)}{T_{\text {high }}-T_{\text {low }}}\right] \cdot\left(T_{\text {avg }}-T_{\text {low }}\right)
$$

From this heat balance equation, CCC can be found using equation 2 .
$I=\sqrt{\frac{Q_{c}+Q_{r}-Q_{s}}{R\left(T_{\text {avg }}\right)}}$

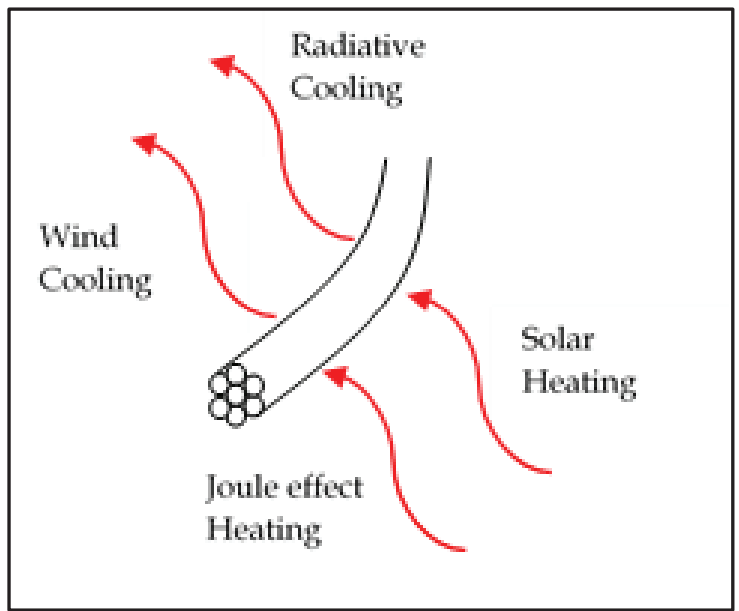

Figure 1 - Illustration of Conductor Cooling and Heating Methods

Convective heat loss can be divided into two types. They are natural convection and forced convection. Natural convection occurs during still air condition. Cool air surrounding hot conductor is heated and is replaced by the cool surrounding air. Forced convection occurs when blowing air moving past the conductor carries the heated air away. Forced cooling has a high cooling capacity than natural cooling. There are two equations to calculate forced convection heat loss. $Q_{c 1}$ is for low wind speeds but underestimates forced convection at high wind speeds. The equation to calculate $Q_{c 2}$ is for high wind speeds but underestimates forced convection heat loss at low wind speeds. At any wind speed, larger value of the two is the forced convection heat loss rate.

$$
\begin{aligned}
& Q_{c 1}=K_{\text {angle }}\left[1.01+1.35 \cdot N_{R e}^{0.52}\right] \cdot k_{f} \cdot\left(T_{s}-T_{a}\right) \\
& Q_{c 2}=K_{\text {angle }} \cdot 0.754 \cdot N_{R e}^{0.6} \cdot k_{f} \cdot\left(T_{s}-T_{a}\right)
\end{aligned}
$$

Where,

$K_{\text {angle }}=1.194-\cos \emptyset+0.194 \cdot \cos 2 \varnothing$
$+0.368 \cdot \sin 2 \varnothing$

$N_{R e}=\frac{D_{0} \cdot \rho_{f} \cdot V_{w}}{\mu_{f}}$

$K_{\text {angle }}$-Wind direction factor

$N_{R e^{-}}$Dimensionless Reynolds number

$V_{w}$-Speed of air stream at conductor

$D_{0}$ - Outside diameter of conductor

$\rho_{f}$ - Density of air

$\mu_{f}$ - Thermal conductivity of air at temperature

$\varnothing$ - Angle between wind and axis of conductor 
Natural convection heat loss happens with zero wind speed. The heat loss rate for the natural convection is shown in equation 5 .

$Q_{c n}=3.645 \cdot \rho_{f}^{0.5} \cdot D_{0}^{0.75} \cdot\left(T_{s}-T_{a}\right)^{1.25}$

$T_{s}$ - Conductor surface temperature

$T_{a}$ - Ambient air temperature

Energy transmitted by the radiation to the surroundings is called radiated heat loss. This happens when the conductor is heated above the ambient temperature. The heat loss rate depends on the difference between the conductor temperature and ambient temperature, and surface condition of the conductor and emissivity. The radiated heat loss rate is shown in equation 6.

$Q_{r}=17.8 \cdot D_{0} \cdot \epsilon \cdot\left(\left[\frac{T_{S}+273}{100}\right]^{4}-\left[\frac{T_{a}+273}{100}\right]^{4}\right)$

Heat energy from the sun provides heat energy to the conductor. The solar heat gain depends on the position of the sun in the sky, solar constant, orientation of the conductor, conductor's surface condition, etc. Equation 7 from IEEE 738 (2012) [3] is used to calculate solar heat gain of a conductor.

$Q_{s}=\alpha \cdot Q_{s e} \cdot \sin \hat{0} \cdot A^{\prime}$

Ô- Effective angle of incidence of the sun's rays

$A^{\prime}$ - Projected area of conductor

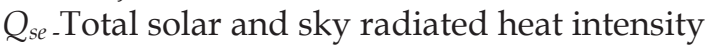

\section{Methodology}

The CCC of the transmission lines in Sri Lanka has been calculated since ages using STR method. As it underestimates the real line capacity, in this paper, a study has been done to find the advantages of RTTR for some selected $132 \mathrm{kV}$ transmission lines in Sri Lanka. The objective is to exploit the available capacity of existing overhead transmission lines, thus reducing investments in replacing conductors or constructing new lines. This method can be a practical solution for increasing transmission line capacity in cases of emergency overloading requirement as well.

The RTTR techniques may be applied to overhead transmission lines to increase their ratings, particularly heavily loaded lines. This requires the weather monitoring stations to monitor ambient temperature, wind speed and wind direction near the transmission lines. The solar intensity values used in this paper have been taken from ASHRAE standards for Sri Lanka. The solar intensity values will be varying with the month. Values of solar intensity will be reducing if a cloud covers the transmission lines. Since this impact helps to increase the line rating further (positive impact), the coverage of clouds has not been taken to account in this study.

On the other hand, for safe operation of transmission lines, the sag should be carefully reviewed to comply with the increased conductor rating. Sag monitoring techniques have to be done in order to ensure the sag of the critical spans. Before applying RTTR method to the existing lines, the sag of the line should be verified with the maximum allowable conductor temperature. In this research, the above design has been done using PLS CADD software.

Five transmission lines have been selected to analyse the dynamic thermal rating values with weather pattern. The lines have been selected to cover the entire country, to include the weather parameters of different parts of the country in the research. These transmission lines have been selected with both ACSR Zebra and ACSR Lynx conductors to analyse how RTTR method can vary with conductor parameters. Table 1 shows the selected transmission lines for this research.

Ambient temperature is one of the parameters which determines the current carrying capacity. Regional differences in the ambient temperature of Sri Lanka are mainly due to the altitude of the location. The transmission lines have been selected to cover higher and lower altitudes of Sri Lanka to analyse RTTR for different ambient temperatures.

Table 1 - Transmission Line Data of Selected Transmission Lines

\begin{tabular}{|l|c|c|c|c|}
\hline Transmission Line & Conductor & $\begin{array}{c}\text { Voltage } \\
(\mathbf{k V})\end{array}$ & $\begin{array}{c}\text { No of } \\
\text { Towers }\end{array}$ & $\begin{array}{c}\text { Line } \\
\text { Length } \\
(\mathbf{k m})\end{array}$ \\
\hline Puttalam - Maho Line & Zebra & 132 & 137 & 42 \\
\hline Embilipitiya - Matara Line & Lynx & 132 & 142 & 52 \\
\hline Ratnapura - Balangoda Line & Zebra & 132 & 102 & 40 \\
\hline Bolawatta - New Chilaw Line & Lynx & 132 & 73 & 23 \\
\hline Varuniya - Kilinochchi Line & Zebra & 132 & 238 & 66 \\
\hline
\end{tabular}


Sri Lanka has two monsoon seasons which are southwest monsoon from May to September and the northeast monsoon from December to February. Some transmission lines have been selected in the windy area of Sri Lanka to analyse the behaviour of RTTR with varying wind patterns.

As mentioned above, RTTR method is applied to the lines to analyse dynamic thermal rating at different locations with different weather patterns. Table 2 shows some specific reasons for the selection of these transmission lines.

Table 2 - Basis for the Selection of Transmission Lines

\begin{tabular}{|c|c|}
\hline Transmission Line & Reasons for selection \\
\hline Puttalam - Maho Line & $\begin{array}{l}\text { This line is located in a windy area. The line facing } \\
\text { south - west monsoon. }\end{array}$ \\
\hline $\begin{array}{l}\text { Ratnapura - Balangoda } \\
\text { Line }\end{array}$ & $\begin{array}{l}\text { Line is travel through hilly area. Ambient temperature } \\
\text { is lower compared to other selected lines. The line is } \\
\text { located in the central part of the country. }\end{array}$ \\
\hline $\begin{array}{l}\text { Bolawatta - New } \\
\text { Chilaw Line }\end{array}$ & $\begin{array}{l}\text { Now this line has ACSR Lynx conductor. It gets } \\
\text { overloaded regularly. The line has been } \\
\text { reconstructing using upper rating conductor (ACSR } \\
\text { Lynx to ACSR Zebra). }\end{array}$ \\
\hline $\begin{array}{l}\text { Embilipitiya - Matara } \\
\text { Line }\end{array}$ & $\begin{array}{l}\text { Terrain pattern is variable from Matara to } \\
\text { Embilipitiya. This line is facing South-West } \\
\text { monsoon. Line is located in southern part of the } \\
\text { country. }\end{array}$ \\
\hline $\begin{array}{l}\text { Vavuniya - } \\
\text { Kilinochchi Line }\end{array}$ & $\begin{array}{l}\text { Dry climate and line is facing North-East wind } \\
\text { season. Line is located in northern part of the country }\end{array}$ \\
\hline
\end{tabular}

\subsection{Identification of Critical Span}

Before using RTTR method to the lines, it is important to identify critical span of the line to ensure the safety of people. When a line has been overloaded, critical span will be the first span which violates the electrical clearance. But a transmission line may travel through different climatic areas. One section of a transmission line can be in a different weather area than the other section. But, at a given time, only one critical span can be there for the entire line. A normal span becomes a critical span when maximum sag point is closer to the electrical clearance line. This will happen when the conductor meets its highest allowable conductor temperature.

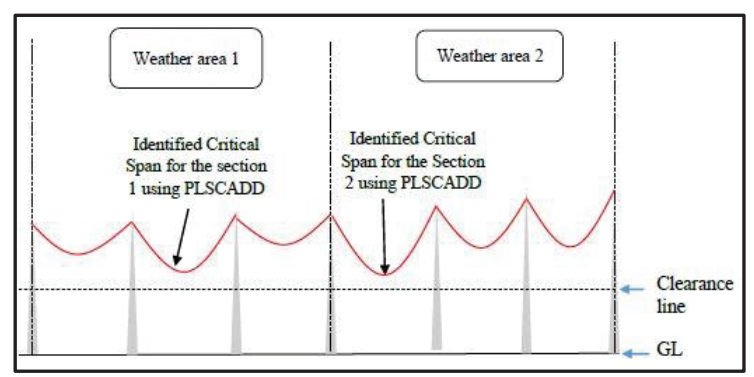

Figure 2 - Illustration of Variation in Critical Spans according to Weather Variation

\subsection{Weather Data}

To analyse the lines using RTTR method, weather data have to be collected near the transmission lines. Weather data from Weather stations near transmission lines have been collected using www.accuweather.com. For example, Embilipitiya - Matara line has seven weather stations near the line. To analyse the real time dynamic method, the line was divided according to the weather stations. These weather stations have hourly predicted ambient temperature and wind velocity weather data.

For the weather station selection, the distance from the transmission line sections to weather stations were measured. The weather station which has the minimum distance from a line section, is selected as weather station for that line section. According to this, two-line sections may have one weather station and there may be a weather station which is not closer to any line section. The figure below describes the selection criteria used to select weather station of a transmission line.

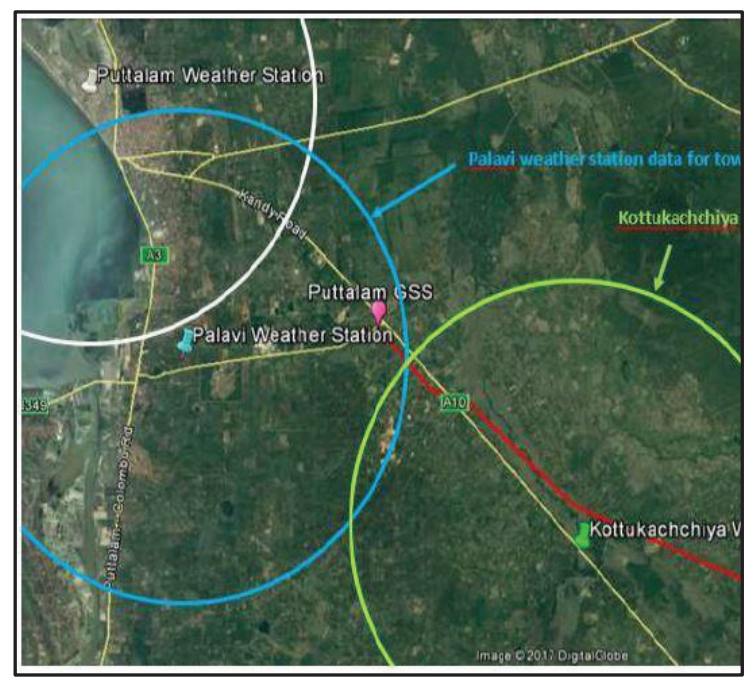

Figure 3 - Weather Station Selection Criteria

\subsection{Collecting Weather Data}

Weather data have been collected using www.accuweather.com with one-hour 
intervals. The ambient temperature, wind speed and wind angle have been collected for all weather stations of five transmission lines. Figure 4 shows sample weather data from Accuweather website.

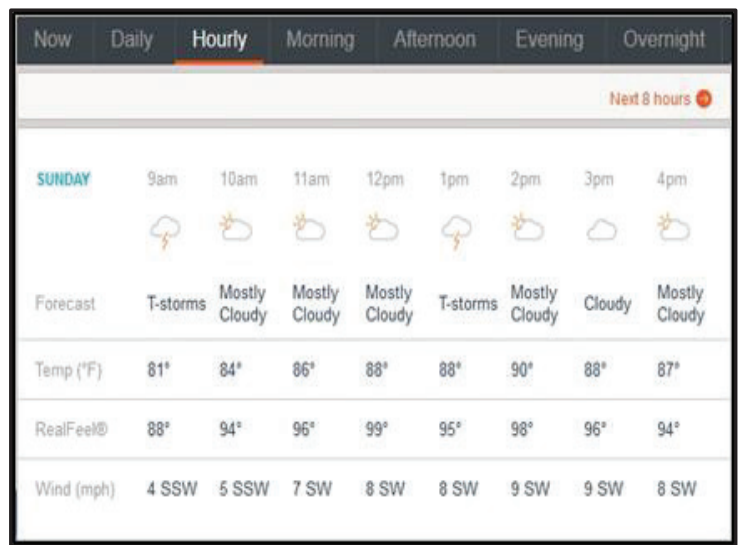

Figure 4 - Hourly Weather Data of a Weather Station in www.accuweather.com

The ambient temperature and wind speed data have been taken for the calculation of RTTR.

Figure 5 shows the variation in ambient temperature with time, which has been taken from the Accuweather website.

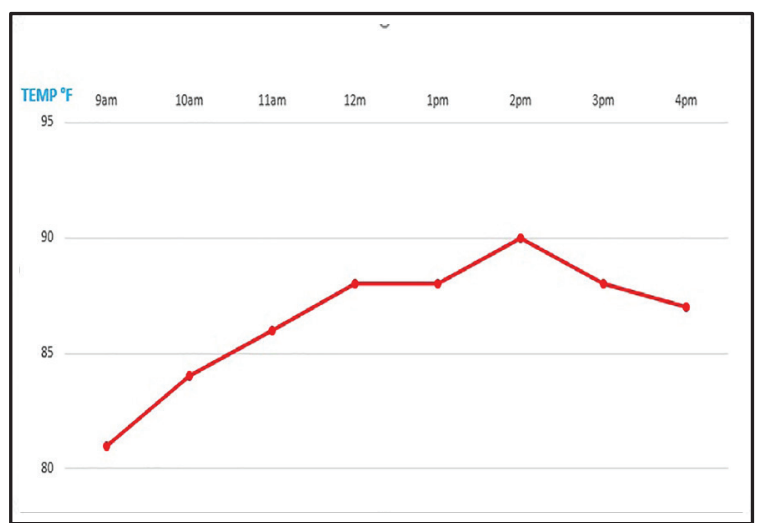

Figure 5 -Ambient Temperature with Time of a Weather Station in www.accuweather.com

\subsection{Solar Intensity}

The solar intensity values have been taken from "ASHRAE handbook 1981 fundamentals" for $8^{\circ}$ North Latitude, which can be used for Sri Lanka. Chapter 27 in this handbook provides the hourly solar intensity. Using these solar intensity values, the variation in solar intensity with time is plotted as shown in Figure 6.

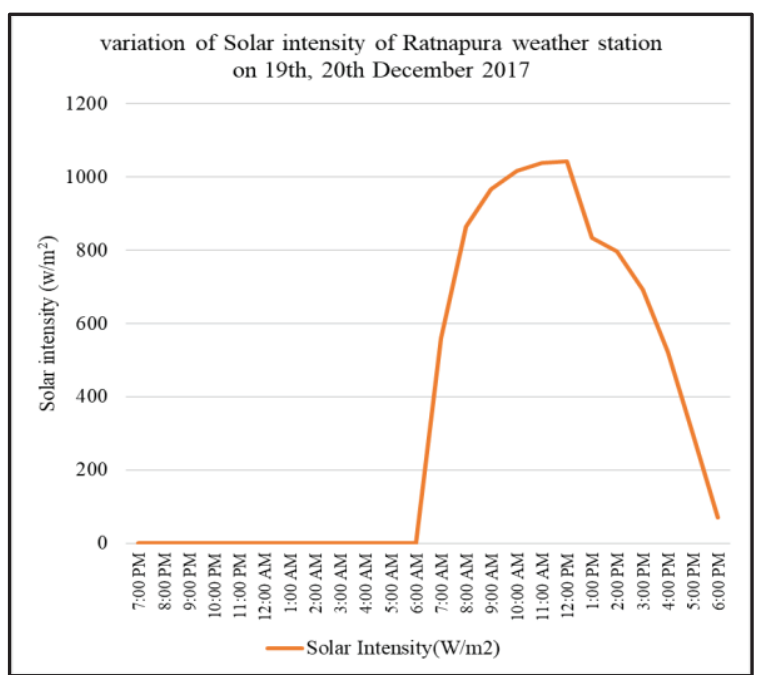

Figure 6 - Solar Intensity Variation with Time

\subsection{PLS CADD Design}

Thermal expansion caused by the increase of conductor temperature can result in the dropping beneath its safety clearance. To ensure safety, the actual line has to modify with actual data. Using actual line inputs, the PLS CADD design has to be designed. Then the critical span of the sections and maximum allowable conductor temperature can be identified. Final output of PLSCADD design of a line section in profile view, plan view and 3D view are shown in Figure 7, 8 and 9, respectively.

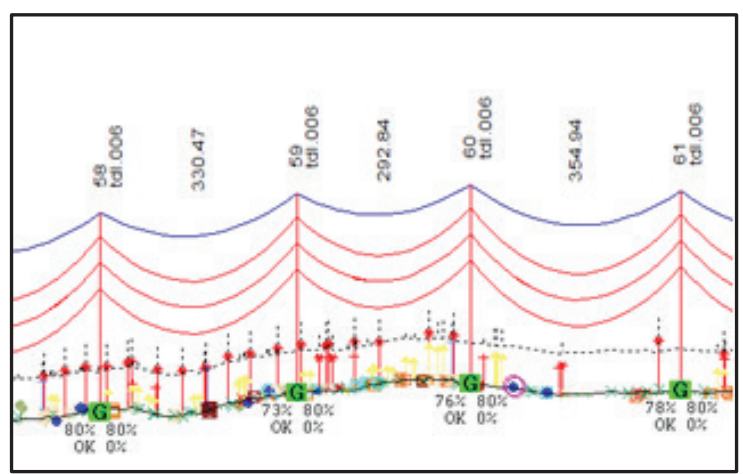

Figure 7 - Profile View of Bolawatta-New ChilawLine in PLSCADD Software

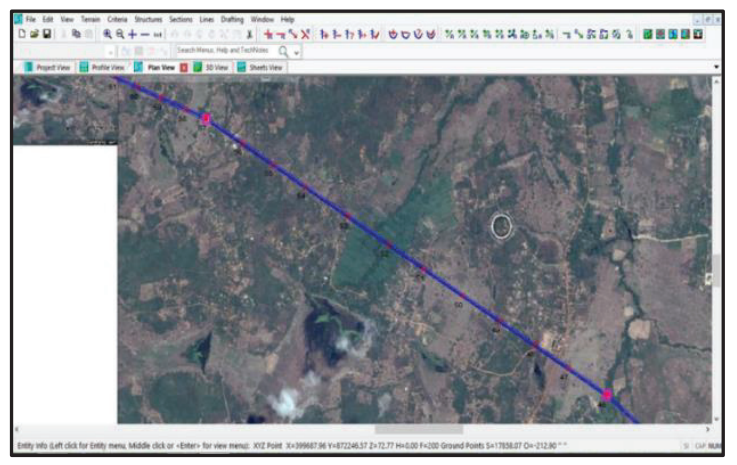

Figure 8 - Plan View of Puttalam-MahoLine in PLSCADD Software 


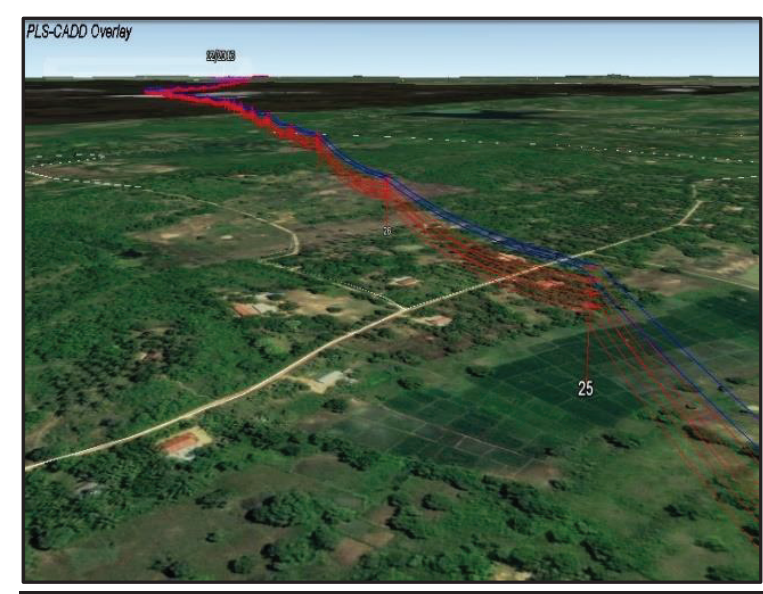

Figure 9 - 3D View of Bolawatta-New Chilaw Line in PLSCADD Software

\subsection{Calculating Real Time Thermal Rating}

CCC of every line section divided according to weather stations has been calculated for every hour within 24 hours of a random day. Figure 10 shows the solar intensity, wind speed and ambient temperature of Section 37-75 of Ratnaura - Balangoda $132 \mathrm{kV}$ transmission line using Pelmadulla weather station data on $19^{\text {th }}$ and $20^{\text {th }}$ December, 2017. The extracted wind and temperature data from particular weather station at considered time period exhibits very minimum change in values. According to the data, the RTTR values have been calculated according to IEEE 738 (2012)[3].

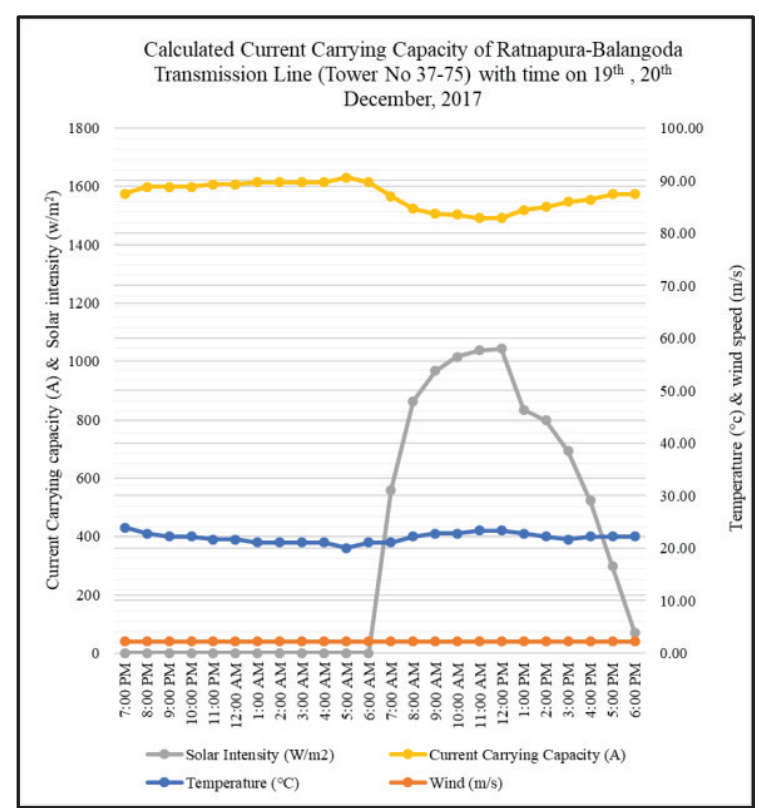

Figure 10 - CCC of a Section of RatnapuraBalangoda Transmission Line

Similarly, the CCC using RTTR method has been calculated for other sections of this line. Since the weather varies from one weather station to the other, the CCC also changes. Figure 11 shows the CCC using RTTR method of all the sections on 19th and 20th December, 2017 and STR value of Ratnapura - Balangoda $132 \mathrm{kV}$ transmission line.

Figure 11 shows the calculated CCC of sections of Ratnapura - Balangoda $132 \mathrm{kV}$ transmission line. At a given time, the safest (without violating clearance as specified in utility technical specification) CCC is the lowest CCC of all sections (minimum value of calculated values). When current increases above the lowest CCC, then the conductor touches the electrical clearance line. So, further loading will be violating the clearance. Therefore, the safest CCC is the lowest CCC of all sections. Figure 12 shows the RTTR and STR values of Ratnapura - Balangoda transmission line on $19^{\text {th }}$ and $20^{\text {th }}$ December, 2017.

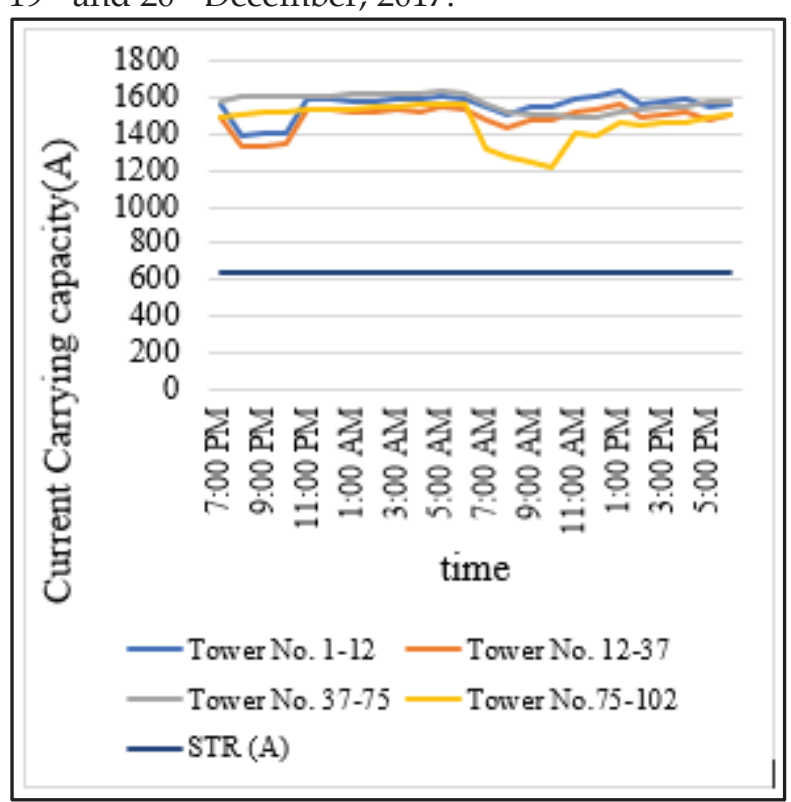

Figure 11 - CCC of all Sections of Ratnapura - Balangoda line as at $19^{\text {th }} \& 20^{\text {th }}$ December, 2017

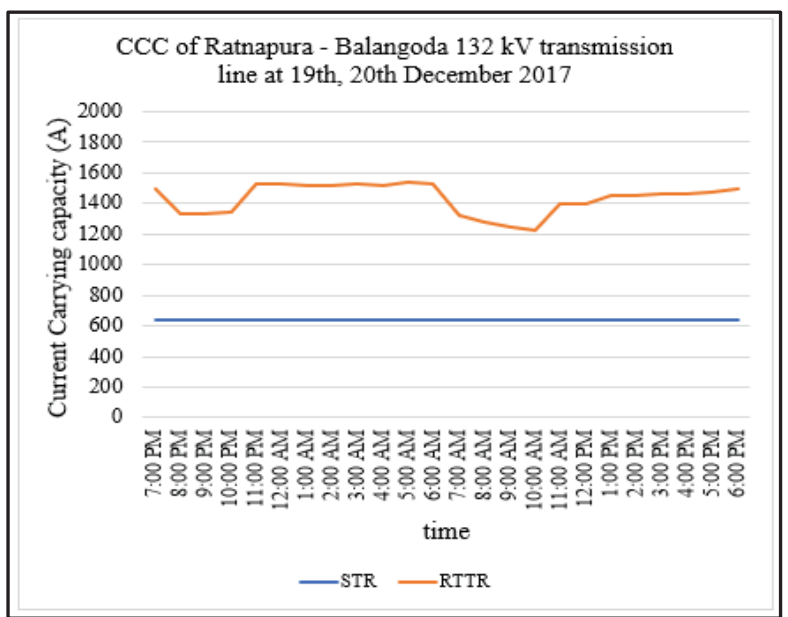

Figure 12 - RTTR and STR Values of Ratnapura-Balangoda $132 \mathrm{kV}$ Transmission line as at $19^{\text {th }} \& 20^{\text {th }}$ December, 2017 


\section{Observations and Results}

CCC for the five selected transmission lines has been calculated as a case study for a random day and results are shown in Figures 13, 14, 15 and 16 below. RTTR values and STR values have been plotted in the same graph to compare the differences.

The difference between RTTR and STR values of Puttalam - Maho $132 \mathrm{kV}$ transmission line was calculated. As per the results, the minimum ampacity difference is $492 \mathrm{~A}$ and the maximum difference is $977 \mathrm{~A}$. The minimum ratio in-between RTTR and STR is 1.65 and maximum ratio is 2.29 . The lowest CCC is observed at $8.00 \mathrm{pm}$ because of the lowest wind speed value of $0.447 \mathrm{~m} / \mathrm{s}$ at Ambanpola weather station. These calculations are done based on the weather parameters taken at 9.00 AM of $8^{\text {th }}$ October, 2017 to 8.00 AM of $9^{\text {th }}$ of October, 2017.

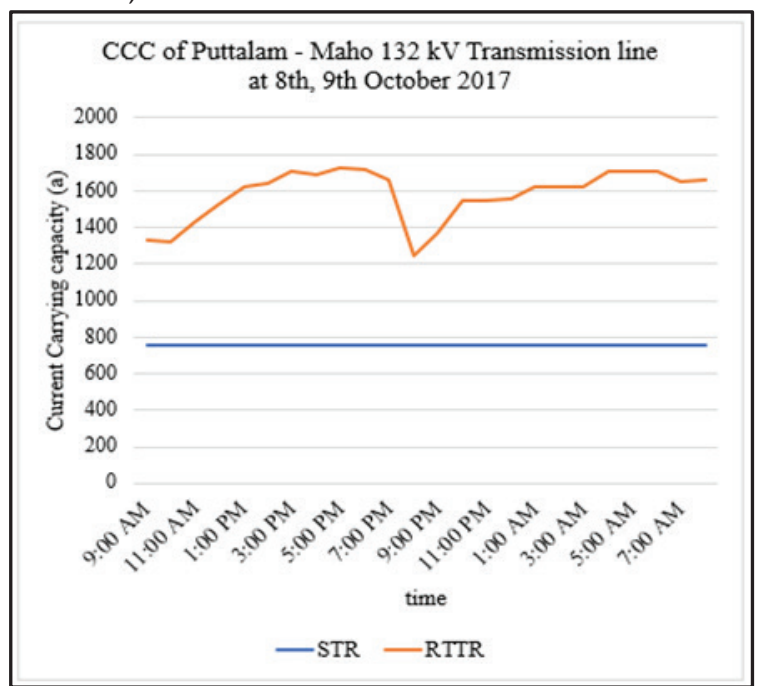

Figure 13 - RTTR Vs STR of PuttalamMahoLine

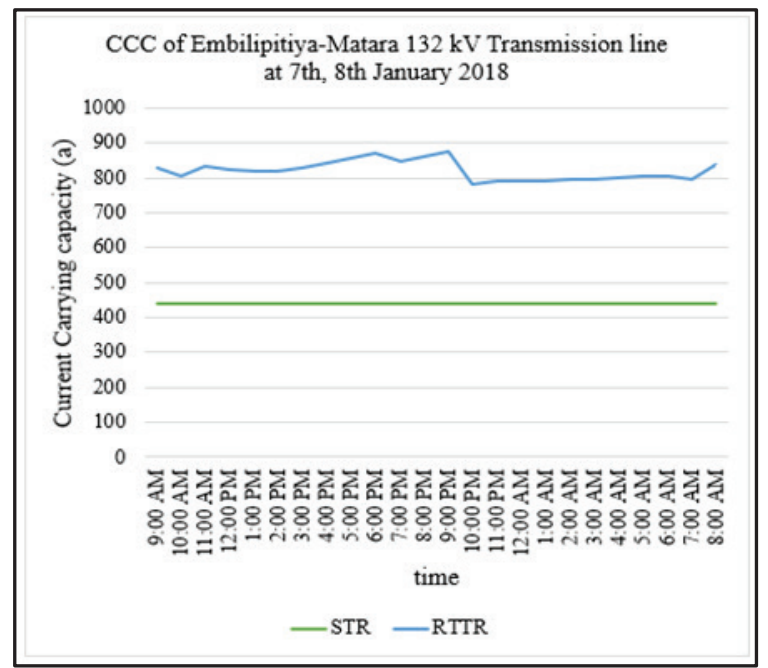

Figure 14 - RTTR Vs STR of EmbilipitiyaMataraLine
The difference between RTTR and STR values of Embilipitiya - Matara $132 \mathrm{kV}$ transmission line was calculated. As per the results the minimum ampacity difference is $342 \mathrm{~A}$ and maximum difference is $434 \mathrm{~A}$. The minimum ratio in-between RTTR and STR is 1.77 and maximum ratio is 1.98 . These calculations are done based on the weather parameters taken at $9.00 \mathrm{AM}$ of $7^{\text {th }}$ January, 2018 to $8.00 \mathrm{AM}$ of $8^{\text {th }}$ of January, 2018.

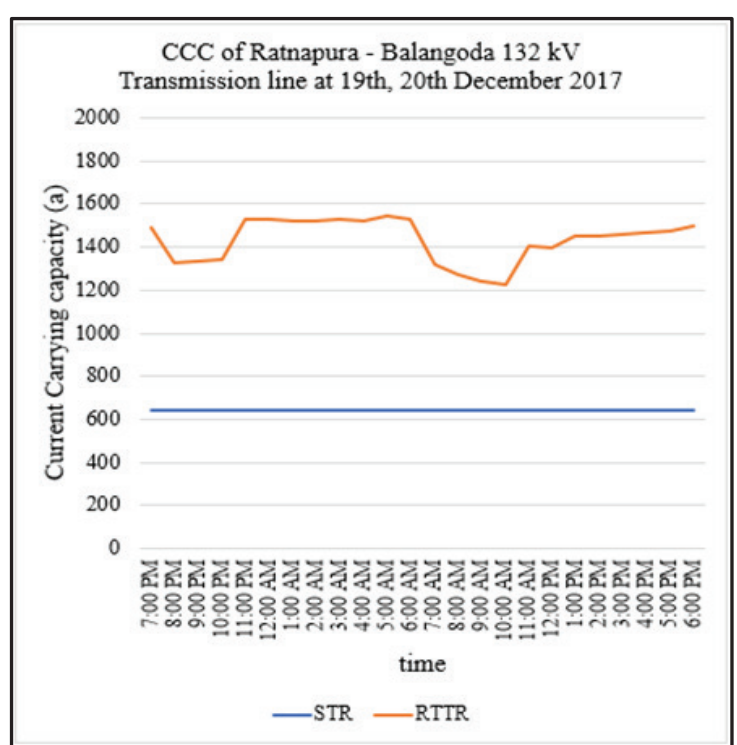

Figure 15 - RTTR Vs STR of RatnapuraBalangoda $132 \mathrm{kV}$ Line

The difference between RTTR and STR values of Ratnapura - Balangoda $132 \mathrm{kV}$ transmission line was calculated. As per the results, the minimum ampacity difference is $583 \mathrm{~A}$ and maximum difference is $902 \mathrm{~A}$. The minimum ratio in-between RTTR and STR is 1.91 and maximum ratio is 2.40. The lowest CCC is observed at $10.00 \mathrm{am}$ because of the lowest wind speed value of $0.89 \mathrm{~m} / \mathrm{s}$ and high solar intensity value of $1016 \mathrm{~W} / \mathrm{m}^{2}$ is observed at Ratnapura weather station. These calculations are done based on the weather parameters taken at 7.00 PM of 19th December, 2017 to 6.00 PM of 20 ${ }^{\text {th }}$ December, 2017. 


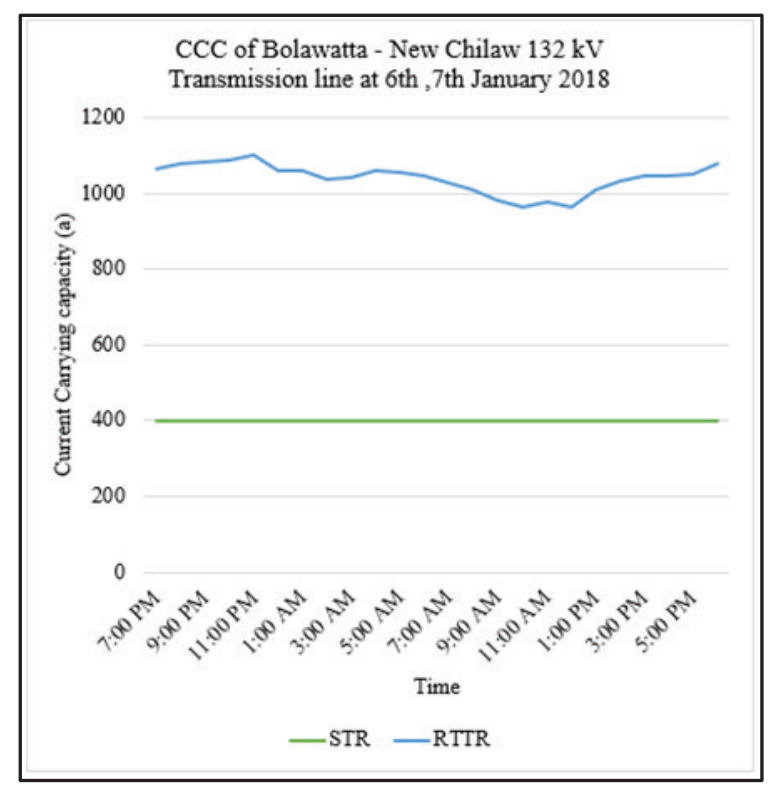

Figure 16 - RTTR Vs STR of Bolawatta -New Chilaw 132 kV Line

The difference between RTTR and STR values of Bolawatta - New Chilaw $132 \mathrm{kV}$ transmission line was calculated. As per the results, the minimum ampacity difference is $564 \mathrm{~A}$ and maximum difference is $701 \mathrm{~A}$. The minimum ratio in-between RTTR and STR is 2.41 and maximum ratio is 2.75 . These calculations are done based on the weather parameters taken at 7.00 PM of $6^{\text {th }}$ January, 2018 to 6.00 PM of $7^{\text {th }}$ January, 2018.

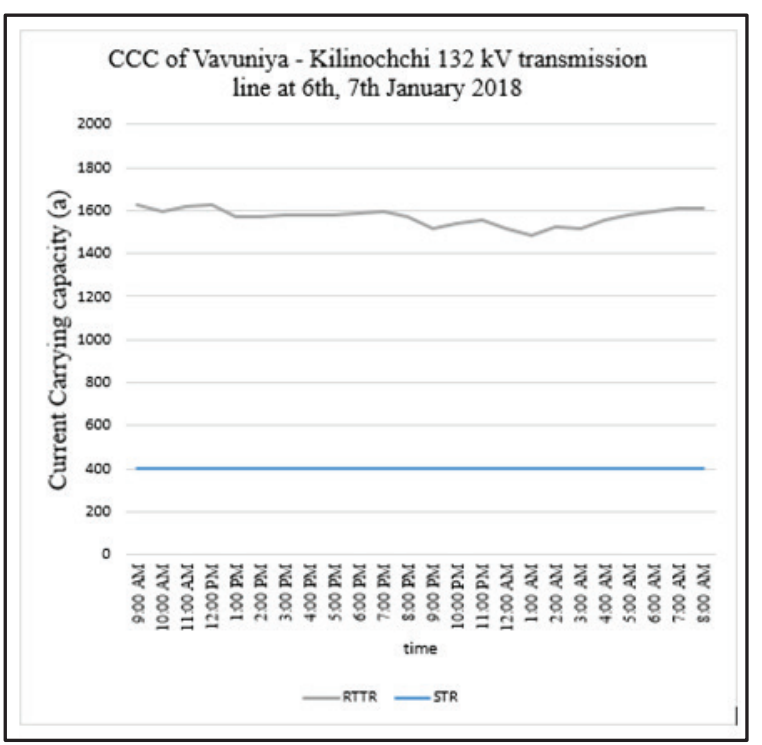

Figure 17 - RTTR Vs STR of VavuniyaKilinochchi Line

The difference between RTTR and STR values of Vavuniya - Kilinochchi $132 \mathrm{kV}$ transmission line was calculated. As per the results, the minimum ampacity difference is $1083 \mathrm{~A}$ and maximum difference is $1227 \mathrm{~A}$. The minimum ratio in-between RTTR and STR is 3.7 and maximum ratio is 4.06 . These calculations are done based on the weather parameters taken at $9.00 \mathrm{AM}$ of $6^{\text {th }}$ January, 2018 to $8.00 \mathrm{PM}$ of $7^{\text {th }}$ January, 2018.

Bolawatta-New Chilaw line is in the final stage of re-construction using Zebra conductor while the existing Lynx conductor line is capable of handling more than the STR value of Zebra conductor. Similarly, Embilipitiya-Matara line gets overloaded frequently (ACE Embilipitiya power plant - $100 \mathrm{MW}$ ) without using the advantage of RTTR method.

However, data collection was done from October, 2017 to January, 2018 along with identified weather stations in considered transmission lines. As per the outcome yields, even in the low windy seasons for Puttlam Maho and Embilipitiya-Matara lines, the application of RTTR method provides significant ampacity enhancement. Hence, the current carrying capacity enhancement is large during south-west monsoon seasons for the aforementioned transmission lines.

\section{Conclusions}

As per the outcomes of this study, the following conclusions were made regarding the usage of RTTR method in the transmission network of Sri Lanka.

-RTTR method can increase CCC of a line significantly compared to STR values used for existing transmission lines.

- RTTR method can be applied in an emergency situation for a predetermined time span.

- Transmission line construction and uprating can be delayed by permits, funds, social/environmental issues and political influences. In such cases, short-term use of real-time dynamic thermal ratings can be economically and operationally advantageous. Re-conductoring and re-construction of existing lines can be avoided or postponed by adopting RTTR method.

-Wind speeds in transmission corridors correlate with wind power generation. Realtime ratings can offer the most economical solutions for use of transmission line capacity 
by using lower rating conductors (smaller diameter).

- If there are generation clusters wherein regions connected by lines which have lower capacity than a dispatchable combined generation, RTTR method can be used.

-This increases capacity on congested transmission lines and also enables increased power transfers. Most importantly, applying RTTR method reduces the high cost thermal generations which are used only to minimize the transmission constraints as in the Sri Lankan system. Using more low-cost power plants would result in a reduced unit price for customers.

\section{References}

1. Ceylon Electricity Board, CEB Technical Specifications - Employer's Requirements Part B of Bidding Document, vol. 5 of 8 .

2. Bayliss, C. R., and Hardy, B., Transmission and Distribution Electrical Engineering, 3rd ed.

3. IEEE Standard for Calculating the CurrentTemperature Relationship of Bare Overhead Conductors, IEEE Std 738-2012.

4. David M. Greenwood, Jake P. Gentle, Kurt S. Myers, Peter J. Davison, Isaac J.West, Jason W.Bush, Grant L. Ingram and Matthias C. M. Troffaes., "A comparison of Real-Time Thermal Rating Systems in the U.S and U.K," IEEE Trans. Power Del., vol. 29, no. 4, August 2014.

5. BolunXu, AndreasUlbig, Goran Andersson, "Impacts on Dynamic Line Rating on Power Dispatch Performance and Grid Integration of Renewable Energy Sources", 4th IEEE PES Innovative Smart Grid Tech. Europe, Copenhegen, 2013.

6. IEC Standard 61597 "Overhead electrical conductors - Calculation methods for stranded bare conductors", 1st ed., 1995-03. 